\title{
PSIKOEDUKASI KELUARGA MENINGKATKAN KEPATUHAN MINUM OBAT ODGJ DI PUSKESMAS KEDATON BANDAR LAMPUNG
}

\author{
Sulastri ${ }^{1}$, Yeyen Kartika ${ }^{2}$ \\ ${ }^{1}$ Jurusan Keperawatan, Poltekkes Tanjungkarang \\ ${ }^{2}$ Poskeskel Penengahan Raya, Bandar Lampung \\ Email: sulasdes@gmail.com
}

\begin{abstract}
Family Psychoeducation Improving Medication Adherence in ODGJ in Primary Health Care Kedaton Bandar Lampung. People with mental disorders (ODGJ), the syndrome with a variety of causes with travel acute and chronic diseases. Clients generally experience a fundamental deviation, characteristic of thought and perception, as well as the affect that do not fit. Psychiatric disorders is expected to recur $50 \%$ in the first year, $70 \%$ the second year, and $100 \%$ in the fifth year after the treatment. This condition briefly unsettled the market because of lack of support from their families and communities. Need appropriate interventions to improve family support, especially in care and treatment. This study aims to determine the influence of family psychoeducation of family support in improving medication adherence in ODGJ in Primary health care Kedaton Bandar Lampung. Research with quantitative approach, quasi experimental pre and post test without control group. A sample of 30 people is the family that is the client's primary care giver. Based on the test pair t-test is known to have an increase in family support and medication adherence after psychoeducation keluuarga clients with a p-value of 0.000 . Suggested holder of a mental health program coordinated with officers village health post (poskeskel) to provide periodic monitoring of the family to always treat the patient optimally included assisting when taking the drug and control once a month nearest health stewardship. Furthermore, family psychoeducation can be used as a routine agenda for a nursing intervention in family ODGJ.
\end{abstract}

Keywords: Family psychoeducation, Medication adherence, ODGJ

\begin{abstract}
Abstrak: Psikoedukasi Keluarga Meningkatkan Kepatuhan Minum Obat ODGJ di Puskesmas Kedaton Bandar Lampung. Orang dengan Gangguan jiwa (ODGJ), mengalami sindrom dengan variasi penyebab dengan perjalanan penyakit akut dan kronis. Ganguan jiwa diperkirakan akan kambuh $50 \%$ pada tahun pertama, $70 \%$ pada tahun kedua,dan $100 \%$ pada tahun ke lima pasca perawatannya. Kondisi ini terjasi karena kurang dukungan dari keluarga dan lingkungannya. Perlu intervensi yang tepat untuk meningkatkan dukungan keluarga khususnya dalam perawatan dan pengobatan. Penelitian ini bertujuan mengetahui pengaruh psikoedukasi keluarga tehadap dukungan keluarga dalam meningkatkan kepatuhan minum obat pada ODGJ di Wilayah Kerja Puskesmas Kedaton Bandar Lampung. Penelitian dengan pendekatan kuantitatif, desain quasi experiment pre and pos test without control grup. Sampel sebanyak 30 orang merupakan keluarga yang merupakan care giver utama pasien. Berdasarkan Uji pair t-test diketahui ada peningkatan dukungan keluarga dan kepatuhan minum obat pasien setelah dilakukan psikoedukasi keluuarga dengan $p$-value $=0,000$. Disarankan pemegang program kesehatan jiwa melakukan koordinasi dengan petugas pos kesehatan kelurahan (poskeskel) untuk memberikan pemantauan secara periodik pada keluarga agar senantiasa merawat pasien secara optimal termasuk mendampingi saat minum obat dan kontrol satu bulan sekali kepelayanan kesehatan terdekat. Selanjutnya psikoedukasi keluarga bisa dijadikan sebagai agenda rutin untuk sebagai intervensi keperawatan pada keluarga ODGJ.
\end{abstract}

Kata kunci: Psikoedukasi keluarga, Kepatuhan minum obat, ODGJ

Komitmen dalam pemberdayaan Orang dengan gangguan jiwa (ODGJ) diperkuat dengan diterbitkannya Undang-undang Nomor 18 tahun 2014 tentang Kesehatan Jiwa, yang ditujukan untuk menjamin setiap orang agar dapat mencapai kualitas hidup yang baik, serta memberikan pelayanan kesehatan secara terintegrasi,

komprehensif,

dan berkesinambungan melalui upaya promotif, preventif, kuratif, dan rehabilitatif (Kemenkes, 2014).

Secara garis besar, Undang-undang tersebut mengamanatkan tentang perlunya peran serta masyarakat dalam melindungi dan 
memberdayakan ODGJ dalam bentuk bantuan berupa: tenaga, dana, fasilitas, pengobatan bagi ODGJ dan perlindungan terhadap tindakan kekerasan, menciptakan lingkungan yang kondusif, memberikan pelatihan keterampilan, serta mengawasi penyelenggaran pelayanan di fasilitas yang melayani ODGJ (Kemenkes, 2014).

Gangguan jiwa merupakan deskripsi sindrom dengan variasi penyebab, banyak yang belum diketahui dengan pasti dan perjalanan penyakit tidak selalu bersifat kronis, pada umumnya ditandai adanya penyimpangan yang fundamental, karakteristik dari pikiran dan persepsi, serta adanya afek yang tidak wajar atau tumpul (Maslim, 2002, dalam Yusuf, Fitriyasari \& Nihayati, 2014).

Gangguan jiwa adalah sindrom pola prilaku seseorang yang secara khas berkaitan dengan sesuatu gejala penderita (Distress) atau hendaya (Impairment) didalam satu atau lebih, fungsi yang penting dari manusia yaitu fungsi psikologik, prilaku biologik dan gangguan itu tidak hanya terletak di dalam hubungan antara orang itu tetapi juga dengan masyarakat (Maslim, 2002 \& Maramis, 2010, dalam Yusuf, Fitriyasari \& Nihayati, 2014).

Organisasi kesehatan dunia WHO menyebutkan bahwa biaya yang dikeluarkan untuk pembelanjaan obat di negara-negara berkembang antara $20-40 \%$ terhadap total biaya kesehatan sedangkan di negara maju antara 10$20 \%$, disebutkan juga bahwa $50-90 \%$ pasien di negara berkembang membayar biaya pengobatan secara swadaya (tidak ditanggung asuransi). Khusus untuk Indonesia, harga obat tergolong mahal yang disebabkan oleh lebih dari $90 \%$ bahan baku obat harus diimpor dari luar negeri (Dunia Farmasi, 2010 dikutip oleh Febriani Ruri 2011).

Kejadian yang dapat menyebabkan gangguan kejiwaan pada anggota keluarga berdampak pada anggota keluarga lain. Kondisi ini membuat anggota keluarga menjadi terbebani secara materi dan imateri. Kehilangan hari-hari produktiftif tidak hanya terjadi pada ODGJ, tetapi anggota keluarga yang lain, karena harus merawat anggota keluarga yang sakit.

Keluarga sebagai pemberi perawatan utama pasien berperan dalam menentukan cara atau asuhan yang diperlukan pasien di rumah. sebaliknya disfungsi keluarga merupakan salah satu penyebab gangguan pada anggota. Pelayanan kesehatan jiwa yang ada merupakan fasilitas yang membantu pasien dan keluarga dalam mengembangkan kemampuan mencegah terjadinya masalah, menanggulangi berbagai masalah dan mempertahankan keadaan adaptif.
Salah satu faktor penyebab kambuh gangguan jiwa adalah keluarga yang tidak tahu cara menangani prilaku pasien di rumah. Menurut Sullinger (1988, dalam Nasir, A \& Muhith, A, 2010), angka kekambuhan pasien gangguan jiwa cukup tinggi. Diperkirakan resiko kambuh 50\% pada tahun pertama, $70 \%$ pada tahun kedua, dan $100 \%$ pada tahun ke lima setelah pulang dari rumah sakit karena perlakuan yang salah selama dirumah dan di masyarakat.obat berperan penting menjadi penyebab kekambuhan pasien. Penanganan yang tepat merupakan solusi bagi masalah ini. Beberapa hasil penelitian terdahulu menunjukkan manfaat psikoedukasi keluarga.

Berdasarkan pada penelitian yang dilakukan Sulastri (2015), tentang pengaruh Psikoedukasi Keluarga terhadap kemampuan keluarga merawat pasien gangguan jiwa di Wilayah Kerja Puskesmas Natar Lampung Selatan dengan menggunakan Desain Quasi Experiment Pre Pos Test pada kelompok intervensi dan kontrol menunjukan adanya pengaruh psikoedukasi keluarga terhadap kemampuan merawat pasien gangguan jiwa. Hal ini tampak dari meningkatnya kemampuan merawat pasien gangguan jiwa pada kelompok intervensi.

Dari hasil penelitian Rahayu (2011), Pengaruh Psikoedukasi Keluarga Terhadap Dukungan Psikososial Keluarga Pada Anggota Keluarga Dengan Penyakit Kusta Di Kabupaten Pekalongan. Hasil uji statistik didapatkan dukungan psikologis nilai $p$ sebesar $0,019(p<\alpha)$, dan dukungan sosial $p$ sebesar $0,035 \quad(p<\alpha)$ sehingga dapat disimpulkan bahwa terdapat perbedaan yang signifikan dukungan psikologis dan sosial keluarga antara kelompok intervensi dan kelompok kontrol dalam merawat anggota keluarga yang menderita kusta setelah emberikan psikoedukasi keluarga.

Hasil penelitian yang dilakukan Cindy Margareta Polak (2009) Hubungan Motivasi Kesembuhan Dengan Kepatuhan Minum Obat Pada Pasien TB Paru Dewasa Di Eka Hospital BSD Tanggerang dengan menggunakan uji Chisquare didapatkan dari 58 responden dengan motivasi kesembuhan rendah ada 21 responden $(36,2 \%)$ yang tidak patuh minum obat sedangkan dari 28 responden yang patuh minum obat terdapat 17 responden $(29,3 \%)$ dengan motivasi sembuh yang tinggi. Hasil OR di dapatkan 3,606 yang berarti responden dengan motivasi sembuh rendah yang mempunyai peluang 3 kali untuk responden yang tidak patuh minum obat dibandingkan pasien yang motivasi sembuh tinggi tapi patuh minum obat $(\mathrm{p}<0,05)$. 
Penelitian yang dilakukan Rahmi Imelsa (2012) Pengaruh Asuhan Keperawatan Pada Pasien, Keluarga Dan Peran Pengawasan Minum Obat Terhadap Kemanidian Dan Kepatuhan Berobat. Prevelensi Schizophrenia di kersamanah adalah sebesar 2.6/1000 jiwa, 39,8\% pasien drop out brobat. Penelitian ini bertujuan mengetahui pengaruh asuhan keperawatan pada pasien, keluarga dan peran PMO (terapi keperawatan) terhadap kemandiran dan kepatuhan berobat. Penelitian ini menggunakan Quasy Eksperiment dengan Pruposive Sampling. Hasil penelitian ini menunjukan terdapat perubahan bermakna kemandirian dan kepatuhan berobat setelah diberikan terapi keperawatan $(p$-value $<\alpha=0,05)$. Terhadap hubungan erat antara kemandirian dan kepatuhan berobat ( $p$-value $<\alpha=0,005)$.

Kecamatan Kedaton merupakan wilayah yang cukup padat di Bandar Lampung. Kedaton terbagi menjadi 7 kelurahan dan 1 Puskesmas Pembantu (pustu) Sukamenanti yang ada dikecamatan Kedaton Kota Bandar Lampung, pada tahun 2014 Kedaton berpenduduk 45.808 jiwa, pada tahun 2015 jumlah penduduk meningkat menjadi sebanyak 47.399 jiwa.

Diperkirakan ada sekitar 100 penduduk yang mengalami gangguan jiwa, 70 diantaranya sudah dikunjungi. 50\% dari 70 pasien yang sudah dirawat mengalami putus obat. Berdasarkan survey awal yang dilakukan sebagian pasien mengatakan merasa jenuh karena pengobatan yang terlalu lama dan merasa sudah semubuh. Keluarga mengatakan tidak menyarankan untuk melanjutkan pengobatan karena ketidak tahuan dan kesibukan yang dialami.

Sebagian pasien melakukan kunjungan ke puskesmas Kedaton hanya melakukan kontrol pada bulan pertama setelah terdiagnosa, dan sebagian pasien lainnya yang sudah berobat \pm 2 sampai 3 bulan tidak mengunjungi puskesmas untuk karena berbagai alasan, seperti dikarenakan tidak mempunyai BPJS dan tidak mempunyai biaya untuk transportasi mengantar pasien, pengobatan. Berdasarkan hasil wawancara kepada 10 pasien yang mengalami gangguan jiwa berserta keluarga yang memiliki anggota keluarga dengan gangguan jiwa, 3 orang diantaranya mengatakan sudah sembuh dan 6 orang mengatakan malas atau bosan minum obat, keluarga tidak memahami bahwa pengobatan harus dilakukan dalam waktu yang lama dan keluarga merasa belum ada penyelesain dari masalah tersebut.

Belum ada intervensi khusus yang diberikan oleh puskesmas untuk mengantisipasi putus obat yang dialami oleh pasien. Keluarga sebagai perawat utama berperan penting untuk

menghindari kekambuhan pasien. Oleh karena itu perlu adanya penanganan masalah terhadap masalah yang dialami oleh keluarga dan anggotanya yang sakit. Salah satu program pelayanan CMHN (Community Mental Health Nursing) yang dapat dilakukan untuk keluarga yang mengalami masalah gangguan jiwa strategi pelaksanaan tindakan keperawatan secara individu dan kelompok bagi pasien dan keluarga. Kegiatan untuk keluarga salah satunya psikoedukasi keluarga.

\section{METODE PENELITIAN}

Penelitian ini menggunakan jenis penelitian Kuantitatif, Desain Quasi Experiment Pre Pos Test. Populasi penelitian ini adalah seluruh anggota keluarga yang mempunyai anggota keluarga dengan gangguan jiwa di wilayah kerja Puskesmas Kedaton Bandar Lampung yang berjumlah 70 orang. Instrumen yang digunakan berupa kuasioner A berisi data responden dan kuasioner $\mathrm{B}$ berisi pernyataan keluarga tentang kedisiplinan pasien minum obat yang dibagikan kepada keluarga pasien dan hasil wawancara terhadap pasien. Setelah data dikumpulkan dilakukan analisa univariat berupa presentase tiap variabel, dan analisa bivariat menggunakan uji T-independen.

\section{HASIL PENELITIAN}

A.

\begin{tabular}{ccccc} 
Tabel 1. & $\begin{array}{c}\text { Distribusi } \\
\text { Keluarga } \\
\text { Psikoedukasi Keluarga }\end{array}$ & $\begin{array}{c}\text { Skor } \\
\text { Sebelum }\end{array}$ & $\begin{array}{r}\text { Pengetahuan } \\
\text { Diberikan }\end{array}$ \\
$\begin{array}{c}\text { Pengetahuan } \\
\text { sebelum } \\
\text { penyuluhan }\end{array}$ & Mean & Median & Min & Maks \\
\hline 30 & 5,60 & 5,50 & 0,00 & 9,00 \\
\hline
\end{tabular}

Dari tabel di atas dapat dilihat bahwa kelompok intervensi yang belum diberikan psikoedukasi keluarga belum mengetahui tentang peran keluarga dalam meningkatkan kepatuhan minum obat pada pasien.

\begin{tabular}{ccccc} 
Tabel 2. Distribusi & $\begin{array}{c}\text { Skor } \\
\text { Keluarga } \\
\text { Psikoedukasi Keluarga }\end{array}$ & \multicolumn{2}{c}{$\begin{array}{c}\text { Pengetahuan } \\
\text { Diberikan }\end{array}$} \\
$\begin{array}{c}\text { Setelah } \\
\begin{array}{c}\text { Pengetahuan } \\
\text { setelah } \\
\text { penyuluhan }\end{array}\end{array}$ & Mean & Median & Min & Maks \\
\hline 30 & 6,70 & 7,00 & 4,00 & 9,00 \\
\hline
\end{tabular}


Dari tabel 2 di atas dapat dilihat bahwa kelompok intervensi yang sudah diberikan psikoedukasi keluarga dapat mengetahui tentang peran keluarga dalam meningkatkan kepatuhan minum obat pada pasien.

\section{B. ANALISIS BIVARIAT}

Tabel 3. Perbandingan Hasil Pengukuran Sebelum Diberikan Psikoedukasi dan Setelah Diberikan Psikoedukasi terhadap Pengetahuan Keluarga

\begin{tabular}{|c|c|c|c|c|}
\hline Variabel & Mean & $\begin{array}{l}\text { Standar } \\
\text { Deviasi }\end{array}$ & $\begin{array}{c}\text { Standar } \\
\text { Error } \\
\text { Mean }\end{array}$ & $\begin{array}{c}p- \\
\text { value }\end{array}$ \\
\hline $\begin{array}{l}\text { Sebelum } \\
\text { diberikan } \\
\text { psikoedukasi }\end{array}$ & 5,6000 & 2,04434 & ,37324 & 0,000 \\
\hline $\begin{array}{l}\text { Setelah } \\
\text { diberikan } \\
\text { psikoedukasi }\end{array}$ & 6,7000 & 1,31700 & 24045 & \\
\hline
\end{tabular}

Berdasarkan tabel 3 nilai pengetahuan keluarga tentang peran keluarga dalam meningkatkan kepatuhan minum obat sebelum diberikan psikoedukasi 5,6000 dengan standart deviasi 2,04434, nilai setelah diberikan psikoedukasi 6,7000 dengan standar deviasi 1,31700. Nilai perbedaan mean sebelum dan setelah diberikan psikoedukasi adalah $-1,10000$. Hasil uji $\mathrm{t}$ dependen didapatkan nilai $p$ value $=0,000$. Berarti

$p$-value $\leq \alpha(0,05)$ maka dapat disimpulkan bahwa ada pengaruh terhadap nilai sebelum diberikan psikoedukasi keluarga dan setelah diberikan psikoedukasi keluarga.

\section{PEMBAHASAN}

Dari hasil penelitian diperoleh bahwa pengetahuan keluarga tentang peran keluarga dalam meningkatkan kepatuhan minum obat sebelum diberikan prikoedukasi dan setelah diberikan psikoedukasi menunjukan nilai yang signifikan, dilihat dari nilai mean bertambah yaitu 5,60 menjadi 6,70 dari hasil uji paired sampel t-test diperoleh $p$-value $=0,000$, yang artinya terdapat perbedaan atau terdapat pengaruh yang signifikan pengetahuan keluarga tentang peran keluarga dalam meningkatkan kepatuhan minum obat pada kelompok intervensi pretest dan postest.

Menurut Stuart dan Sundeen (2005), Psikoedukasi keluarga merupakan salah satu bentuk terapi perawatan kesehatan jiwa keluarga dengan cara memberikan informasi dan edukasi melalui komunikasi terapeutik. Hasil penelitian menunjukan keluarga yang sudah mendapatkan psikoedukasi menunjukan adanya pengetahuan keluarga tentang peran keluarga dalam meningkatkan kepatuhan minum obat pada pasien, dan membantu pasien dalam pengobatan secara rutin.

Pemberian metode ini menunjukkan bahwa psikoedukasi lebih efektif di bandingkan dengan penyuluhan kesehatan ataupun hanya supportif terapi, banyak kelebihan dari psikoedukasi keluarga seperti pengkajian atas kendala yang Ndialami oleh keluarga terkaji lebih dalam proses pengkajian yang di awali sesi, kemudian terapis akan menginformasikan tentang gangguan jiwa 30dimulai dari pengertian, tanda gejala dan pengobatan yang wajib di minum obat.

Hasil ini sesuai dengan pendapat Lestari, (2011) bahwa prinsip belajar merupakan proses yang dilakukan seumur hidup manusia memiliki kemampuan untuk belajar sejak lahir sampai akhir hayat. Pemberian edukasi memberikan informasi pada keluarga tentang cara perawatan pasien pada gangguan jiwa melalui aktivitas ini terjadi proses pembelajaran yang dilakukan oleh keluarga dengan menyerap informasi yang diberikan dan mengaplikasikan langsung pada anggota keluarganya.

Menurut Stuart dan Sundeen (2005), Psikoedukasi keluarga merupakan salah satu bentuk terapi perawatan kesehatan jiwa keluarga dengan cara memberikan informasi dan edukasi melalui komunikasi terapeutik. Hasil penelitian menunjukan keluarga yang sudah mendapatkan psikoedukasi menunjukan adanya pengetahuan keluarga tentang peran keluarga dalam meningkatkan kepatuhan minum obat pada pasien, dan membantu pasien dalam pengobatan secara rutin.

Berdasarkan hasil ini jelas terbukti pemberian psikoedukasi keluarga lebih efektif di bandingkan dengan penyuluhan kesehatan ataupun hanya supportif terapi, banyak kelebihan dari psikoedukasi keluarga seperti pengkajian atas kendala yang dialami oleh keluarga terkaji lebih dalam proses pengkajian yang di awali sesi, kemudian terapis akan menginformasikan tentang gangguan jiwa dimulai dari pengertian, tanda gejala dan pengobatan yang wajib di minum obat. Menurut penelitian yang dilakukan Sulastri (2015), Pengaruh Psikoedukasi Keluarga Terhadap Kemampuan Keluarga Merawat Pasien Gangguan Jiwa Di Wilayah Kerja Puskesmas Natar Lampung Selatan Terapi psikoedukasi keluarga yang tidak diberi perlakuan kontrol peningkatan nilai tidak terjadi secara signifikan yaitu pretest sebesar 11,88 dan postest sebesar 
11,94 yang berarti peningkatannya sebanyak 0,06 . Sebaliknya responden pada kelompok intervensi pretest 13,63 postest 30,5 peningkatan sebanyak 16,67. Dari hasil uji paried sampel $t$ test pada kelompok intervensi diperoleh $p$-value $=$ 0,000 yang berarti terdapat perbedaan pre-post, pada kelompok kontrol $p$-value 0,889 tidak dapat perbedaan saat pre-post.

Menurut Friedman (1998) dan Nasir, A \& Muhith, A (2010), menjelaskan bahwa keluarga dalam memenuhi kebutuhan kehidupannya memiliki fungsi-fungsi dasar keluarga. Fungsi dasar tersebut tebagi menjadi lima fungsi yang salah satunya adalah fungsi afektif, yaitu fungsi keluarga untuk pembentukan dan pemeliharaan kepribadian anak-anak, pemantapan kepribadian orang dewasa, serta pemenuhan kebutuhan psikologi para anggotanya. Apabila fungsi efektif ini tidak dapat berjalan semestinya, maka akan terjadi gangguan psikologi yang berdampak pada kejiwaan dari keseluruhan unit keluarga tersebut. Dari hasil penelitian yang dilakukan Sulastri (2015), Pengaruh Psikoedukasi Keluarga Terhadap Kemampuan Keluarga Merawat Pasien Gangguan Jiwa Di Wilayah Kerja Puskesmas Natar Lampung Selatan bahwa keluarga mampu merawat pasien gangguan jiwa pada kelompok intervensi pre-post menunjukan nilai signifikan di lihat dari nilai mean bertambah yaitu 16,67, dan hasil uji paried sampel t-test pada kelompok intervensi diperoleh $p$-value $=0,000$ yang berarti terdapat perbedaan pre-post, pada kelompok kontrol $p$-value 0,889 tidak dapat perbedaan saat pre-post.

Menurut Penelitian yang dilakukan Rahmi Imelsa (2012) Pengaruh Asuhan Keperawatan Pada Pasien, Keluarga Dan Peran Pengawasan Minum Obat Terhadap Kemandirian Dan Kepatuhan Berobat. Prevelensi Schizophrenia di kersamanah adalah sebesar 2.6/1000 jiwa, 39,8\% pasien drop out brobat. Penelitian ini bertujuan mengetahui pengaruh asuhan keperawatan pada pasien, keluarga dan peran PMO (terapi keperawatan) terhadap kemandiran dan kepatuhan berobat. Hasil penelitian ini menunjukan terdapat perubahan bermakna kemandirian dan kepatuhan berobat setelah diberikan terapi keperawatan ( $p$-value $<\alpha=0,05)$. Terhadap hubungan erat antara kemandirian dan kepatuhan berobat ( $p$-value $<\alpha=0,005$ ).

Kepatuhan adalah tingkat prilaku pasien yang setuju terhadap instruksi atau petunjuk yang diberikan dalam bentuk terapi apapun yang di tentukan, baik diet, latihan, pengobatan atau menepati janji pertemuan dengan dokter. Menurut sackett (1976 dalam Neil Niven, 2002) mendefinisikan kepatuhan pasien "sejauh mana pasien sesuai dengan ketentuan yang diberikan oleh profesional kesehatan".

Hasil penelitian ini menunjukan terdapat perubahan bermakna kemandirian dan kepatuhan berobat setelah diberikan terapi keperawatan ( $p$ value $<\alpha=0,05$ ). Terhadap hubungan erat antara kemandirian dan kepatuhan berobat ( $p$ value $<\alpha=0,005)$. Meningkatkan kemandirian pasien terhadap kepatuhan berobat.

Untuk itu dari hasil penelitian ini diharapkan perawat dapat melakukan psikoterapi khususnya psikedukasi keluarga. Serta diperlukan dukungan petugas kesehatan dan masyarakat seperti kader kesehatan jiwa keluarga agar keluarga dapat secara rutin mengikuti kegiatan pertemuan khususnya terapi psikoedukasi keluarga agar keluarga mendapatkan informasi secara berkelanjutan dalam meningkatkan kepatuan minum obat dengan cara-cara yang di ajarkan.

\section{SIMPULAN}

Ada pengaruh yang bermakna pemberian psikoedukasi keluarga terhadap dukungan keluarga dalam meningkatkan kepatuhan pasien minum obat. Disarankan pada pemegang program kesehatan jiwa untuk dapat menjadwalkan secara rutin pertemuan pada keluarga untuk terlaksananya psikoedukasi bagi keluarga. Memasang poster-poster difasilitas kesehatan seperti pos kesehatan kelurahan dan praktek suasta tentang pentingnya kepatuhan minum obat bagi pasien gangguan jiwa.

\section{DAFTAR PUSTAKA}

Imelsa, Rahmi. 2012. Pengaruh Asuhan Keperawatan pada Pasien, Keluarga dan Peran Pengawasan Minum Obat terhadap Kemanidian dan Kepatuhan Berobat.
Lestari, A. 2011. Pengaruh Terapi Psikoedukasi terhadap pengetahuan dan tingkat kecemasan keluarga dalam merawat anggota keluarga yang mengalami Tuberkulosis Paru lib.ui.ac.id/file?file $=$ digital/20280268- 
T\%20Arena\%20Lestari.pdf (diperoleh 12 Juni 2015).

Nasir, A \& Muhith, A. 2010. Dasar-dasar Keperawatan Jiwa. Penerbit: Salemba Medika.

Niven, Neil. 2002. Psikologi Kesehatan Pengantar Untuk Perawat \& Profesional Kesehatan Lain. Jakarta: EGC.

Polak, Margeta, C. 2009. Hubungan Motivasi Kesembuhan dengan Kepatuhan Minum Obat pada Pasien TB Paru Dewasa di Eka Hospital BSD Tanggerang.

Rahayu, A, D. 2011. Pengaruh Psikoedukasi Keluarga terhadap Dukungan Psikososial Keluarga pada Anggota Keluarga dengan Penyakit Kusta di Kabupaten Pekalongan.
Sulastri. 2015. Pengaruh Psikoedukasi Keluarga terhadap Kemampuan Keluarga Merawat Pasien Gangguan Jiwa di Wilayah Kerja Puskesmas Natar Lampung Selatan. Seminar Hasil-Hasil Penelitian - LPPM UNIMUS 2012. ISBN : 978-602-18809-06

Stuart \& Laria. 2005. Principles \& Practice Of Psychiatric Nursing. 7th Edition. St. Louise: Mosby.

Yusuf, Fitryasari. R. P.K \& Nihayati, EN. 2014. Buku Ajar Keperawatan Kesehatan Jiwa. Penerbit: Salemba Medika.

Kemenkes. 2014. Stop Stigma dan Diskriminasi terhadap Orang dengan Gangguan Jiwa. http://www.depkes.go.id/article/view/2014 10270011/odgj.html 